\title{
The Effect of Infliximab on Intestinal Anastomosis Healing in Rats
}

\author{
Oktay Karaköse', Hüseyin Eken ${ }^{1}$, Ali Naki Ulusoy', Hüseyin Koray \\ Topgül', Mehmet Bilgin', Saim Savaș Yürüker', Mustafa Yavuz Gülbahar² \\ ${ }^{1}$ Department of General Surgery, Faculty of Medicine, Ondokuz Mayis University, \\ Samsun, Turkey; \\ ${ }^{2}$ Department of Pathology, Faculty of Veterinary Medicine, Ondokuz Mayis \\ University, Samsun, Turkey
}

Received April 5, 2016; Accepted September 2, 2016.

Key words: Infliximab - Anastomosis - Tumor necrosis factor- $\alpha$-Wound healing

Abstract: Intestinal anastomosis healing is a complex physiological process in which many local and systemic factors play a role. One of the significant cytokines in this process is TNF- $\alpha$. Infliximab is a chimeric monoclonal antibody which binds to TNF- $\alpha$ with high affinity. Although this agent is used in ulcerative colitis and Crohn's disease, intestinal surgery may be required in these patients. In this study it was aimed to determine whether or not there was any negative effect of preoperative single dose infliximab treatment on intestinal anastomosis healing. Two groups of 10 rats were formed. One of these groups was administered with a single dose of infliximab $8 \mathrm{mg} / \mathrm{kg}$ as a 20 -minute intravenous infusion from the femoral vein. Four days after the infusion, a full layer incision was made to the colon and anastomosis was applied to all the rats. At 7 days after anastomosis, the subjects were sacrificed. The anastomosis segment was removed and the bursting pressure was measured.Tissue samples were taken from this segment for hydroxyproline concentration and histopathological examination. A blood sample was taken to measure TNF- $\alpha$ values. No statistically significant difference was determined between the groups in terms of bursting pressure, tissue hydroxyproline concentration or histopathological scoring. A single dose of $8 \mathrm{mg} / \mathrm{kg}$ infliximab administered 4 days preoperatively was not found to have any negative effect on intestinal anastomosis healing in rats.

Mailing Address: Hüseyin Eken, MD., Department of General Surgery, Faculty of Medicine, Ondokuz Mayis University, Samsun, Turkey; e-mail: huseyineken80@hotmail.com 


\section{Introduction}

Many local and systemic factors play a role in intestinal anastomosis healing. Important factors in the extracellular matrix are immune cells which regulate collagen fibres, fibroblasts and wound resistance in the early postoperative healing process. In the normal inflammatory response, monocytes become macrophages by migrating into the wound. The first mediator expressed by macrophages is TNF- $\alpha$. TNF- $\alpha$ is a cytokine of polypeptide structure expressed by activated macrophages and monocytes stimulated by endotoxins, immune complexes, toxins and other inflammation mediators (Mathews, 1981; Comert et al., 2000; Isik et al., 2015a). By increasing collagenase production, collagen synthesis is inhibited. Fibroblast proliferation, IL-6 and PG E2 production increases (Dayer et al., 1985; Regan et al., 1993).TNF- $\alpha$ is one of the important chemical inflammatory mediators in wound healing (Bettinger et al., 1994).

Infliximab is a chimeric monoclonal antibody in the $\lg G_{1}$ subtype which binds with high affinity to both soluble and transmembranous forms of TNF- $\alpha$ (Suzuki et al., 2001). In vivo, infliximab forms stable complexes with human TNF- $\alpha$ and this process is in parallel with bioactivity loss in TNF- $\alpha$ (Suzuki et al., 2001; Nanda et al., 2013). Infliximab is used in the treatment of patients with inflammatory intestinal diseases such as Crohn's disease and ulcerative colitis. However, as it is insufficient in the treatment of the majority of these patients, surgery is still required. While some studies have reported an increase in the risk of anastomosis leakage and other postoperative complications in patients treated with preoperative infliximab (Selvasekar et al., 2007; Mor et al., 2008), others have found no difference (Colombel et al., 2004; Marchal et al., 2004; Kasparek et al., 2012). The differences between the results of these studies may be due to differences in study groups and study plans.

In this study, it was aimed to determine whether or not there was any harmful effect of preoperative single dose infliximab treatment on intestinal anastomosis healing in rats.

\section{Material and Methods}

Approval for the study was granted by the Animal Ethics Committee of Ondokuz Mayis University Faculty of Medicine. The study was conducted at the same university in the Surgical Sciences Research Laboratory. A total of 20 adult male Wistar albino rats were used, each weighing mean $224 \mathrm{~g}$ (range 191-310 g). Throughout the study, the rats were housed under standard conditions (room temperature of $20-24{ }^{\circ} \mathrm{C}$ with $50-60 \%$ humidity) and were fed standard food and water. All the rats were fasted for 12 hours before the surgical intervention. Ketamine- $\mathrm{HCl}$ at a dose of $30-50 \mathrm{mg} / \mathrm{kg}$ administered intraperitoneally was used as anaesthesia and the surgery was performed under sterile conditions.

The rats were separated into 2 groups of 10 , with only 1 group given a single dose of infliximab of $8 \mathrm{mg} / \mathrm{kg}$ administered from the femoral vein as a 20 -minute 
intravenous infusion (Remicade $100 \mathrm{mg}$, Shering-Plough (Brinny) Co. Innishannon, County Cork, Republic of Ireland). Prior to the infliximab administration, approximately $1 \mathrm{cc}$ blood was taken from the tail vein of all the rats for TNF- $\alpha$ value assay. In all the rats a full layer incision was made to the colon and anastomosis was applied. This procedure was applied 4 days after the administration of infliximab. At 7 days after anastomosis, the subjects were sacrificed. The anastomosis segment was removed and the bursting pressure was measured. Tissue samples were taken from this segment for hydroxyproline concentration and histopathological examination. A blood sample was taken to measure TNF- $\alpha$ values.

The groups were formed as:

Group 1: a full layer incision was made to the descending colon and anastomosis was applied $(n=10)$.

Group 2: 4 days after the administration of $8 \mathrm{mg} / \mathrm{kg}$ infliximab as a 20 -minute intravenous infusion, a full layer incision was made to the descending colon and anastomosis was applied $(n=10)$.

At 7 days after anastomosis, all the rats were sacrificed.

\section{Descending colon anastomosis}

Following ketamine- $\mathrm{HCl}$ anaesthesia, the abdomen was entered with a midline incision. With sharp dissection in the segment $3 \mathrm{~cm}$ proximal of the peritoneal reflection, a full layer incision was made. Anastomosis was made one by one using $5 / 0$ prolene suture material. Four days prior to the surgical intervention, the rats in Group 2 were administered $8 \mathrm{mg} / \mathrm{kg}$ infliximab from the femoral vein as a 20-minute intravenous infusion. The parameters related to blood biochemistry and anastomosis healing were examined 7 days after anastomosis in both groups.

\section{Bursting pressure measurement}

A colon segment $4 \mathrm{~cm}$ in length, was resected leaving the anastomosis line in the centre. In the bursting pressure measurement, a volumetric infusion pump, a mercury manometer and saline stained with methylene blue were used. One end of the intestine was connected to the plastic tube coming from the mercury manometer $1.5 \mathrm{~cm}$ from the proximal of the anastomosis and the other end to the plastic tube coming from the volumetric infusion pump. The colon segment attached between the plastic tubes was filled with saline. The intestinal lumen was filled with blue-stained saline at $2.5 \mathrm{ml} / \mathrm{min}$ with the volumetric infusion pump. The rise of the mercury manometer was monitored. The pressure at the moment of bursting was accepted with the methylene blue staining of each sample.

After measuring the bursting pressure, the colon segments were washed with saline and the lumen were opened longitudinally. For standardisation of the measurement of hydroxyproline, samples were taken as $2.2 \pm 0.5 \mathrm{mg}$ and frozen at $-70{ }^{\circ} \mathrm{C}$. Samples were also taken from the anastomosis line for histopathological examination. 


\section{Hydroxyproline concentration measurement}

The hydroxyproline content (as an indicator of the amount of collagen) was measured in the intestine sample which included the anastomosis line and had been stored at $-70{ }^{\circ} \mathrm{C}$ using the method described by Jamall et al. (1981). The results were stated as $\mu \mathrm{g}$ hydroxyproline/mg tissue.

\section{Histopathological examination}

The segment containing the whole anastomosis line was fixed in $10 \%$ formaldehyde then embedded in paraffin. Slices 5 microns in thickness were taken and stained with haematoxylin-eosin and Masson's Trichrome to determine early collagen content and the wound healing score was determined according to the Greenhalgh method (Greenhalgh et al., 1990). In each anastomosis section, the inflammatory cells, neutrophil infiltration, neovascularisation, fibroblastic activity and amount of collagen band were determined. Wound healing was evaluated by a pathologist according to the presence of these cells and scoring was made of values from 1 to 5 . When there were no inflammatory cells, fibroblastic activity was evident, new collagen had formed and neovascularisation was complete, healing was accepted as very good and the reverse situation was evaluated as very poor. For statistical comparison wound healing scores were accepted as: $1=$ very poor, 2 = poor, $3=$ fair, $4=$ good, 5 = very good.

\section{Statistical analysis}

The data obtained from measurements of hydroxyproline, TNF- $\alpha$ and bursting pressure were evaluated for conformity to normal distribution with the Kolmogorov-Smirnov and Shapiro-Wilk tests. As all data showed normal distribution, the Variance Analysis Post-Hoc Tukey HSD test was used in the comparisons between the groups. The anastomosis healing scores were evaluated with the Kruskal-Wallis test as they were not continuous data and did not conform to normal distribution. Data were stated as mean \pm standard deviation (SD) for continuous variables and as median (minimum-maximum) for non-continuous variables. A p-value of $<0.0125$ was accepted as statistically significant.

\section{Results}

TNF- $\alpha$ was not determined in the blood samples taken at the beginning of the study.

No statistically significant difference was determined between the groups in the bursting pressure and hydroxyproline values. A statistically significant difference was determined between the groups in the mean TNF- $\alpha$ concentration on the $7^{\text {th }}$ day of anastomosis healing $(p<0.001)$ (Table 1$)$.

In the histopathological examination of the slices stained with haematoxylineosin, in Group 1 (not administered infliximab), there was an appearance of widespread mononuclear cell infiltration, evident fibroblastic activity, increased 

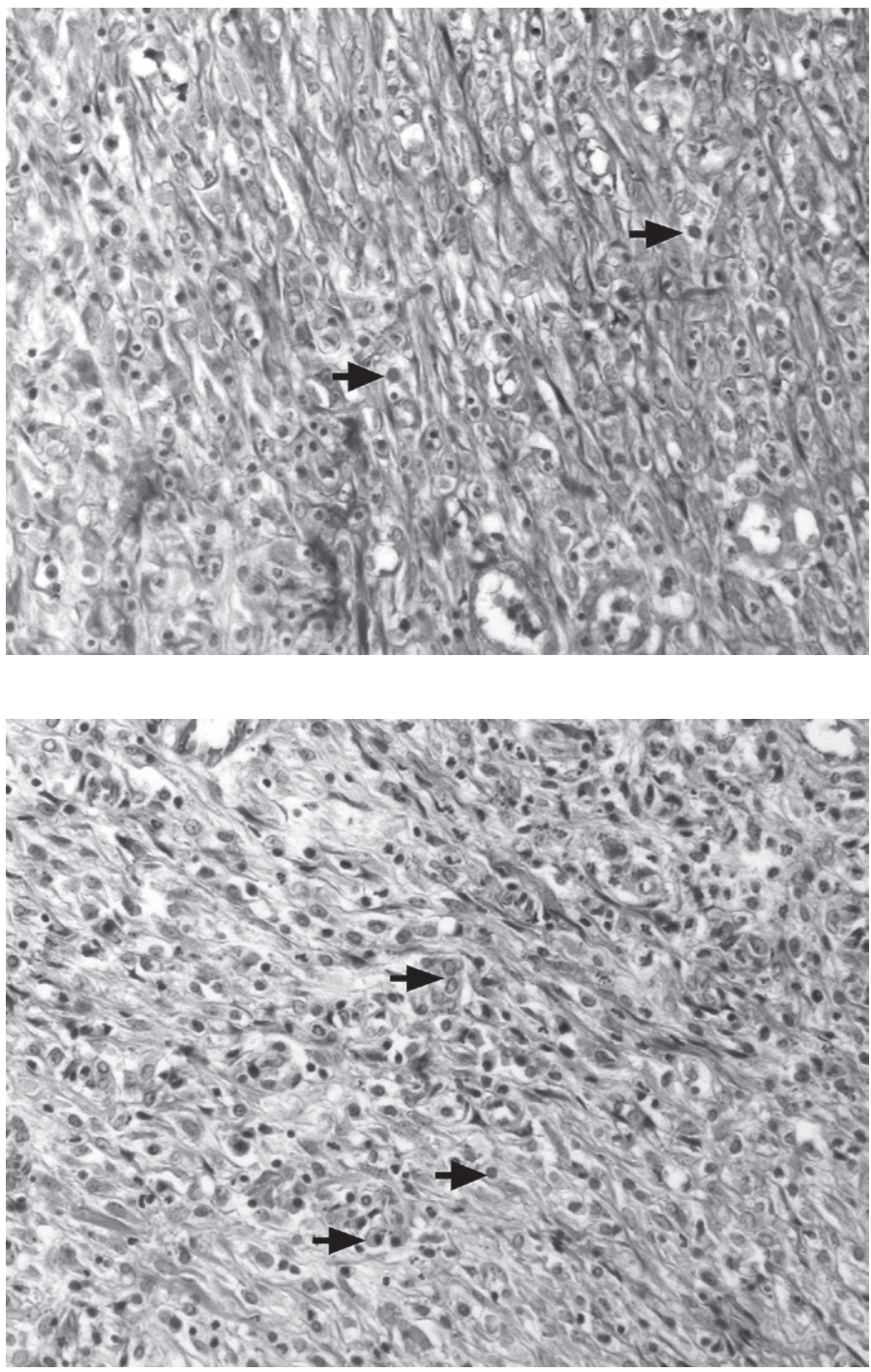

Figure 1 - Histopathology image of Group 1 (not administered infliximab). Widespread mononuclear cell infiltration, evident fibroblastic activity and significant new collagen synthesis. The arrows indicate mononuclear cells.
Figure 2 - Histopathology image of Group 2

(administered infliximab). Widespread mononuclear cell infiltration, new vascular formation, evident fibroblastic activity and collagen synthesis with finer fibres compared to Group 1.

\section{Table 1 - The mean values of the parameters examined and the $p$-values obtained in the comparisons between the groups}

\begin{tabular}{lcccc}
\hline & $\begin{array}{c}\text { Bursting } \\
\text { pressure } \\
(\mathrm{cm} \mathrm{Hg})\end{array}$ & $\begin{array}{c}\text { Tissue hydroxyproline } \\
\text { concentration } \\
(\mu \mathrm{g} / \mathrm{mg} \text { tissue })\end{array}$ & $\begin{array}{c}\text { TNF- } \alpha \\
\text { concentration } \\
(\mathrm{pg} / \mathrm{ml})\end{array}$ & $\begin{array}{c}\text { Histopathological } \\
\text { scoring } \\
(\mathrm{min}-\mathrm{max})\end{array}$ \\
\hline Group 1 & $10.50 \pm 1.58$ & $0.53 \pm 0.06$ & $11.98 \pm 1.31$ & $3(3-4)$ \\
Group 2 & $12.20 \pm 2.44$ & $0.60 \pm 0.09$ & $5.90 \pm 2.64$ & $3(2-4)$ \\
P-value & 0.081 & 0.032 & $<0.001^{*}$ & 0.418 \\
\hline
\end{tabular}

$*_{p}<0.0125$ 
neovascularisation and evident new collagen synthesis (Figure 1). In Group 2 (administered with infliximab), mononuclear cell infiltration was more widespread than in Group 1, there was new vascular formation, evident fibroblast activity and collagen synthesis was determined with an appearance of thinner fibres compared to Group 1 (Figure 2). However, there was no statistically significant difference in the evaluation of the scoring between the groups (Table 1).

\section{Discussion}

TNF- $\alpha$ has a regulating function in the inflammatory phase of wound healing (Bettinger et al., 1994). The migration of neutrophils and other phagocyte cells to the wound area increases the phagocytosis capacity of neutrophils and superoxide anion structure (Mathews, 1981; Comert et al., 2000; Isik et al., 2015a). By increasing the expression of collagenase enzyme, the total collagen amount is reduced. In addition, the production of interleukine-1 and prostaglandin-E are increased in fibroblasts and vascular endothelium (Dayer et al., 1985; Regan et al., 1993). In chronic wound fluids, it has been shown that the increased TNF- $\alpha$ level reduced with time in the healing process (Streit e al., 2006).

Wound healing is a complex physiological process dependent on multiple intrinsic and extrinsic factors which are events such as inflammation, collagen synthesis and angiogenesis. This process can be impaired with the use of pharmacological agents such as corticosteroids, antineoplastic drugs and anti-inflammatory drugs (Papaconstantinou et al., 2014). While some studies have shown the anti-TNF agent, infliximab, to have a negative effect on wound healing (Selvasekar et al., 2007; Mor et al., 2008), others have reached the conclusion that healing is not affected (Colombel et al., 2004; Marchal et al., 2004; Kasparek et al., 2012). Despite the use of this agent in ulcerative colitis and Crohn's disease, intestinal surgery may be necessary in these patients. In this study it was aimed to determine whether or not there was any negative effect of preoperative single dose infliximab treatment on intestinal anastomosis healing in rats.

In a study conducted on rabbits by Frostberg et al. (2014), a single dose of infliximab administered one week preoperatively was found not to have a negative effect on bursting pressure. Papaconstantinou et al. (2014) determined that perioperative administration of infliximab on rats was not the reason for changes in anastomosis bursting pressure and when the postoperative septic status was examined, no difference was seen in comparison with the group not administered infliximab. Inflammation was seen to be lower in the infliximab group and in the protein expression analysis of the anastomosis region, TGFb1 and collagen $\mathrm{V}$ which play a significant role in colon anastomosis were found to be higher in the infliximab group. The authors concluded that preoperatively administered infliximab did not have a negative effect on intestinal anastomosis. In a rabbit study by Jensen et al. (2015), repeated high doses of infliximab were found to significantly reduce the tensile strength of anastomosis. 
In the current study, no difference was found between the groups in respect of anastomosis bursting pressure, hydroxyproline concentration and anastomosis healing scores when the effects of infliximab treatment were compared on intestinal anastomosis. In the histopathological examination, although there were fewer inflammatory cells and finer collagen fibres in the infliximab group, there was no statistically significant difference. That there was no negative effect on anastomosis healing can be considered to be probably due to the single dose of $8 \mathrm{mg} / \mathrm{kg}$ administered 4 days preoperatively. However, for more significant clarification on this subject, further studies are required, primarily at the molecular level because TNF inhibition in the healing process indirectly causes an increase in some molecules. How the effect could occur in total should be examined in detail.

There were some limitations to this study, primarily that while infliximab treatment is given to patients with inflammatory intestinal disease, healthy rat intestine was used in this study. In addition, the number of subjects in the current study was extremely limited and the agent which is used on humans was used on rats. Another limitation was the preoperative dose amount and that it was a single dose. Infliximab is used at the dosage of $5 \mathrm{mg} / \mathrm{kg}$ in Crohn's disease, and ranging from 3 to $10 \mathrm{mg} / \mathrm{kg}$ in rheumatoid arthritis (Siddiqui and Scott, 2005). In an experimental study by Oruc et al. (2004), infliximab treatment of oedematous and necrotising pancreatitis created in rats was determined to have resulted in a significant histopathological regression in oedematous pancreatitis, suppression of neutrophil infiltration and a lessening of complications. Papaconstantinou et al. (2014) administered 5 doses of $5 \mathrm{mg} / \mathrm{kg}$ subcutaneously at 3-day intervals and applied surgery 3 days after the final dose. Frostberg et al. (2014) used a single dose of $10 \mathrm{mg} / \mathrm{kg} \mathrm{IV} \mathrm{one} \mathrm{week} \mathrm{preoperatively} \mathrm{in} \mathrm{rabbits.} \mathrm{In} \mathrm{the} \mathrm{current} \mathrm{study,} \mathrm{the}$ dose of $8 \mathrm{mg} / \mathrm{kg}$ IV, which was effective in pancreatitis, was selected.

In the current study, when the mean TNF- $\alpha$ concentration of the $7^{\text {th }}$ day of anastomosis healing was examined, there was seen to be a statistically significant difference between Groups 1 and $2(p<0.001)$. This result showed the effectiveness of infliximab.

In the definition of the final status of the wound healing, histopathological examination was a subjective method, especially useful in monitoring the infiltration of specific cell types to the wound. To show the effectiveness of wound healing at various clinic conditions more studies must be done (Kesici et al., 2007; Isik et al., 2014, 2015b). In the current study, although finer fibres of new collagen were seen and more widespread mononuclear cell infiltration in Group 2 in the histopathological examination, there was no statistically significant difference compared to Group 1.

\section{Conclusion}

In the current study, no negative effect was determined on intestinal anastomosis healing in rats from a single dose of $8 \mathrm{mg} / \mathrm{kg}$ infliximab administered 4 days 
preoperatively. However, both wound healing and the use of systemic anti-TNF- $\alpha$ is a complex subject in which several mediators have a role. For full clarification, there is a need for further studies, particularly at the molecular level.

\section{References}

Bettinger, D. A., Pellicane, J.V., Tarry, W. C., Yager, D. R., Diegelmann, R. F., Lee, R., Cohen, I. K., DeMaria, E. J. (1994) The role of inflammatory cytokines in wound healing: accelerated healing in endotoxin-resistant mice. J. Trauma 36, 810-813.

Colombel, J. F., Loftus, E.V. Jr., Tremaine, W. J., Pemberton, J. H., Wolff, B. G., Young-Fadok, T., Harmsen, W. S., Schleck, C. D., Sandborn, W. J. (2004) Early postoperative complications are not increased in patients with Crohn's disease treated perioperatively with infliximab or immunosuppressive therapy. Am. J. Gastroenterol. 99, 878-883.

Comert, M., Taneri, F., Tekin, E., Ersoy, E., Oktemer, S., Onuk, E., Düzgün, E., Ayoğlu, F. (2000) The effect of pentoxifylline on the healing of intestinal anastomosis in rats with experimental obstructive jaundice. Surg. Today 30, 896-902.

Dayer, J. M., Beutler, B., Cerami, A. (1985) Cachectin/tumor necrosis factor stimulates collagenase and prostaglandin E2 production by human synovial cells and fibroblasts. J. Exp. Med. 162, 2163-2168.

Frostberg, E., Ström, P., Gerke, O., Qvist, N. (2014) Infliximab’s influence on anastomotic strength and degree of inflammation in intestinal surgery in a rabbit model. BMC Surg. 14, 23.

Greenhalgh, D. G., Sprugel, K. H., Murray, M. J., Ross, R. (1990) PDGF and FGF stimulate wound healing in the genetically diabetic mouse. Am. J. Pathol. 136, 1235-1242.

Isik, A., Eryılmaz, R., Okan, I., Dasiran, F., Firat, D., Idiz, O., Sahin, M. (2014) The use of fibrin glue without surgery in the treatment of pilonidal sinus disease. Int. J. Clin. Exp. Med. 7, 1047-1051.

Isik, A., Peker, K., Soyturk, M., Firat, D., Yoruker, U., Yilmaz, I. (2015a) Diagnostic evaluation and treatment of patients with rectus abdominis hematoma. Cir. Esp. 93, 580-588.

Isik, A., Peker, K., Gursul, C., Sayar, I., Firat, D., Yilmaz, I., Demiryilmaz, I. (2015b) The effect of ozone and naringin on intestinal ischemia/reperfusion injury in an experimental model. Int. J. Surg. 21, 38-44.

Jamall, I. S., Finelli, V. N., Que Hee, S. S. (1981) A simple method determine nanogram levels of 4-hydroxyproline in biological tissues. Anal. Biochem. 112, 70-75.

Jensen, J. S., Petersen, N. B., Biagini, M., Bollen, P., Qvist, N. (2015) Infliximab treatment reduces tensile strength in intestinal anastomosis. J. Surg. Res. 193, 145-152.

Kasparek, M. S., Bruckmeier, A., Beigel, F., Muller, M. H., Brand, S., Mansmann, U., Jauch, K. W., Ochsenkuhn, T., Kreis, M. E. (2012) Infliximab does not affect postoperative complication rates in Crohn's patients undergoing abdominal surgery. Inflamm. Bowel Dis. 18, 1207-1213.

Kesici, H., Ulusoy, A. N., Topgül, K., Pașaoğlu, H., Bayraktar, N., Șenyürek, G., Karaköse, O. (2007) The effect of taurolidine on healing of colonic anastomosis in rats with obstructive jaundice. Ulus. Cerrahi Derg. 23 , 1-9.

Marchal, L., D’Haens, G., Van Assche, G., Vermeire, S., Noman, M., Ferrante, M., Hiele, M., Bueno De Mesquita, M., D'Hoore, A., Penninckx, F., Rutgeerts, P. (2004) The risk of post-operative complications associated with infliximab therapy for Crohn's disease: a controlled cohort study. Aliment. Pharmacol. Ther. 19, 749-754.

Mathews, N. (1981) Production of an anti-tumour cytotoxin by human monocytes. Immunology 44, $135-142$.

Mor, I. J., Vogel, J. D., da Luz, M. A., Shen, B., Hammel, J., Remzi, F. H. (2008) Infliximab in ulcerative colitis is associated with an increased risk of postoperative complications after restorative proctocolectomy. Dis. Colon Rectum 51, 1202-1207. 
Nanda, K. S., Cheifetz, A. S., Moss, A. C. (2013) Impact of antibodies to infliximab on clinical outcomes and serum infliximab levels in patients with inflammatory bowel disease (IBD): a meta-analysis. Am. J. Gastroenterol. 108, 40-47.

Oruc, N., Ozutemiz, A. O., Yukselen, V., Nart, D., Celik, H. A., Yuce, G., Batur, Y. (2004) Infliximab: A new therapeutic agent in acute pancreatitis? Pancreas 28, e1-e8.

Papaconstantinou, I., Zeglinas, C., Gazouli, M., Nastos, K., Yiallourou, A., Lykoudis, P., Evangelou, K., Papalois, A., Papaioannou, M., Vlachogiannakos, J., Tzathas, C. (2014) Effect of infliximab on the healing of intestinal anastomosis. An experimental study in rats. Int. J. Surg. 12, 969-975.

Regan, M. C., Kirk, S. S., Hurson, M., Sodeyama, M., Wasserkrug, H. L., Barbul, A. (1993) Tumor necrosis factoralpha inhibits in vivo collagen synthesis. Surgery 113,173-177.

Selvasekar, C. R., Cima, R. R., Larson, D.W., Dozois, E. J., Harrington, J. R., Harmsen, W. S., Loftus, E. V. Jr., Sandborn, W. J., Wolff, B. G., Pemberton, J. H. (2007) Effect of infliximab on short-term complications in patients undergoing operation for chronic ulcerative colitis. J. Am. Coll. Surg. 204, 956-962.

Siddiqui, M. A. A., Scott, L. J. (2005) Infliximab: A review of its use in Crohn's disease and rheumatoid arthritis. Drugs 65, 2179-2208.

Streit, M., Beleznay, Z., Braathen, L. R. (2006) Topical application of the tumour necrosis factor-alpha antibody infliximab improves healing of chronic wounds. Int. Wound J. 3, 171-179.

Suzuki, S., Kurachi, K., Yokoi, Y., Tsuchiya, Y., Okamoto, K., Okumura, T., Konno, H., Baba, S., Nakamura, S. (2001) Intrahepatic cholangiojejunostomy for unresectable malignant biliary tumors with obstructive jaundice. J. Hepatobiliary Pancreat. Surg. 8, 124-129. 